\title{
ENDODONTIC MANAGEMENT OF UNUSUAL LARGE PULP STONE IN MANDIBULAR CANINE- A CASE REPORT
}

\author{
Payal Jain ${ }^{1}$, Sunil Tejaswi2, Paras Mull Gehlot ${ }^{3}$, Suneeth Shetty 4
}

\author{
1 Postgraduate Student, Department of Conservative Dentistry and Endodontics, JSS Dental College and Hospital, JSS Academy of \\ Higher Education and Research, Mysore, Karnataka. \\ ${ }^{2}$ Reader, Department of Conservative Dentistry and Endodontics, JSS Dental College and Hospital, JSS Academy of Higher Education \\ and Research, Mysore, Karnataka. \\ ${ }^{3}$ Reader, Department of Conservative Dentistry and Endodontics, JSS Dental College and Hospital, JSS Academy of Higher Education \\ and Research, Mysore, Karnataka. \\ ${ }^{4}$ Assistant Professor, Department of Conservative Dentistry and Endodontics, JSS Dental College and Hospital, JSS Academy of Higher \\ Education and Research, Mysore, Karnataka.
}

HOW TO CITE THIS ARTICLE: Jain P, Tejaswi S, Gehlot PM, et al. Endodontic management of unusual large pulp stone in mandibular canine- a case report. J. Evolution Med. Dent. Sci. 2018;7(15):1929-1931, DOI: 10.14260/jemds/2018/434

\section{PRESENTATION OF CASE}

A 25-year-old male reported to the Department of Conservative Dentistry and Endodontics with a chief complaint of pain and swelling in the lower right canine region since three days. Patient reported history of trauma due to self-fall one year back. The tooth was associated with pain and tenderness when chewing food and increased on thermal changes. Intraoral examination revealed an obliteration of vestibule on the right mandibular canine region and tenderness on percussion. Pulp vitality with electric and thermal test elicited no response. Intraoral periapical radiograph revealed diffuse periapical radiolucency and in the pulp chamber space a radiopacity was evident, indicating calcification.

Pulp stones are calcification formed in pulp chamber and sometimes extending to the root canal part. Radiographically, they are easily identified and they appear as radiopaque mass in the pulp space. Normally, pulp stones are found in isolated tooth and rarely all or many teeth are associated with the presence of pulp stones. The present case describes the removal of an $8 \mathrm{~mm}$ long pulp stone in a single mass from a mandibular canine in a patient with generalised occurrence of pulp stones.

Pulp stones are discrete calcifications formed in the pulp chamber or the root canals and may exist freely within pulp tissue or may be attached to or embedded in dentin. ${ }^{1}$ They are also called denticles and vary in size. The presence of pulp stones is frequently noticed on a routine bitewing or periapical radiograph. Pulp stones are a common occurrence. A study on Australian population found the prevalence of $46.1 \%$ in young adults. Occurrences were rare in premolars (0.4\%), but significantly higher in molars $(19.7 \%){ }^{2}$

'Financial or Other Competing Interest': None.

Submission 27-02-2018, Peer Review 22-03-2018,

Acceptance 30-03-2018, Published 09-04-2018.

Corresponding Author:

Dr. Paras Mull Gehlot,

Department of Conservative Dentistry and

Endodontics, JSS Dental College and Hospital,

JSS Academy of Higher Education and Research,

JSS Medical Institutions Campus,

Sri Shivarathreeshwara Nagara,

Mysuru- 570015, Karnataka, India.

E-mail: dr.parasmullj@jssuni.edu.in

DOI: $10.14260 /$ jemds $/ 2018 / 434$
Pulp stones can occur in one or more teeth (or all of the teeth) as well in impacted or erupted teeth for an individual. These are often narrow (especially in anterior) and many a times obstruct the access to canal orifice. They frequently occupy the coronal part of root canal and pose difficulty in root canal therapy. ${ }^{1}$ This could lead to iatrogenic errors during access cavity preparation like gouging pulp chamber and deviation in canal pathway, especially for novice operators.

The present communication aims to report a case of large elongated pulp stone in mandibular canine, which was successfully removed under magnification.

\section{DIFFERENTIAL DIAGNOSIS}

Included pulp necrosis, acute alveolar abscess associated with pulpal stones, denticle or diffuse calcification, phoenix abscess and chronic apical periodontitis.

\section{CLINICAL DIAGNOSIS}

Based on clinical and radiographic findings, a diagnosis of pulpal necrosis with acute dentoalveolar abscess was made and a non-surgical endodontic treatment was planned.

Under rubber dam isolation, local anaesthetic (Lignox A, Indoco Remedies Ltd., Gujarat, India) was administered and access cavity preparation was initiated with a no. 2, round diamond point, until a drop was felt. However, due to the presence of pulp stone the dip in the pulp chamber was not realised. This lead to the deviation in the access cavity preparation and a gouge was unintentionally formed. To prevent further loss of tooth structure, the tooth was examined under dental operating microscope (OPMI pico, Carl Zeiss, Oberkochen, Germany), the calcified mass was visible (Fig. 1A) as an irregular white mass attached to the walls of the pulp chamber; and after careful extension of access cavity, 17\% EDTA (RC prep, Prime Dental Pvt. Ltd., Thane, India) was used in the pulp chamber to soften the space between the pulp stone and the canal wall. Initially, a \#10 K-file (Mani Inc., Tochigi, Japan) was eased between the pulp stone and the canal wall, and once the file became loose a \#20 H-file (Mani Inc., Tochigi, Japan) was gently passed till resistance and the calcified mass was displaced completely out in total (Fig. 1C, D). The length of the calcified mass was measured to be $8 \mathrm{~mm}$ long. Its shape was confirmed to the shape of pulp chamber. After determining the patency of the root canal with \#10K file (Mani Inc., Tochigi, Japan), working length was determined and canal was prepared with sequential irrigation with 17\% EDTA (RC prep, Prime Dental 
Pvt Ltd., Thane, India) and 1\% sodium hypochlorite (Nice Chemicals, India). Calcium hydroxide (RC cal, Prime Dental Pvt. Ltd., Thane, India) intracanal dressing was placed and tooth temporised. On subsequent visit, tooth was obturated with lateral compaction method. The access cavity was restored with composite resin (Tetric N-Ceram, Ivoclar Vivadent AG, Liechtenstein). Post-treatment radiograph revealed satisfactory obturation of the root canal (Fig. 1B).

Further radiographic investigation with an OPG revealed presence of pulp stone in contralateral canine and multiple pulpal calcification in other teeth (Fig. 2).

\section{PATHOLOGICAL DISCUSSION}

The aetiology of pulp stone formation is unclear and controversial. ${ }^{1}$ Common aetiological factors implicated in pulp stone formation include pulp degeneration, age, circulatory disturbances, orthodontic tooth movement, longstanding irritants such as caries, deep fillings and chronic pulp inflammation. Apart from these factors, pulp stones can also be associated with systemic conditions like gout, renal disease and cardiovascular diseases. 3,4

Recently, the discovery of calcifying nanoparticles (CNPs), also referred to as nanobacteria led to novel theories for pathological calcification. ${ }^{5}$

These nanoparticles could produce biogenic carbonate apatite on their cell envelope at all growth phases, which resulted in white biofilm and mineral aggregates closely resembling those found in tissue calcification in the human body. ${ }^{6}$

According to Cook, pulp stones can be found in normal teeth with healthy pulps as well as in carious teeth and periodontally involved teeth. ${ }^{7}$ However, Bergman stated that pulp stones occur mainly in pathologic pulps where the pulp is dead or dying. It is reported that pulp stones may cause discomfort and pain, though they may be present sometimes without any clinical symptoms. ${ }^{8}$ Pulp stones have been noted in patients with systemic or genetic diseases such as dentine dysplasia, dentinogenesis imperfecta and in certain syndromes such as Van der Woude syndrome. ${ }^{1}$

Unusual cases of idiopathic generalised pulp stone formation have been reported, although sometimes a genetic predisposition is also noted. ${ }^{9}$ A pilot study of correlation of pulp stones with cardiovascular disease demonstrated that patients with cardiovascular disease have an increased incidence of pulp stones. ${ }^{3}$

\section{DISCUSSION OF MANAGEMENT}

Importance of Pulp Stones during Endodontic Treatment

1. It is important to interpret the pre-operative radiograph, especially in the presence of pulpal calcification.

2. Calcifications in pulp reduce the cellular component of pulp and interfere with vascularity of surrounding connective tissue. This could make the direct pulp capping to be less successful.

3. Pulpal calcification obstructs the canal orifice and may make the detection of canal orifice challenging, especially in molars. This could lead to iatrogenic errors like gouging or perforation.

4. Magnification and illumination aids in management of severe pulpal calcification and reduce errors during treatment.
5. Ultrasonic tips may facilitate removing the calcifications, especially stones which are of adhered to the floor.
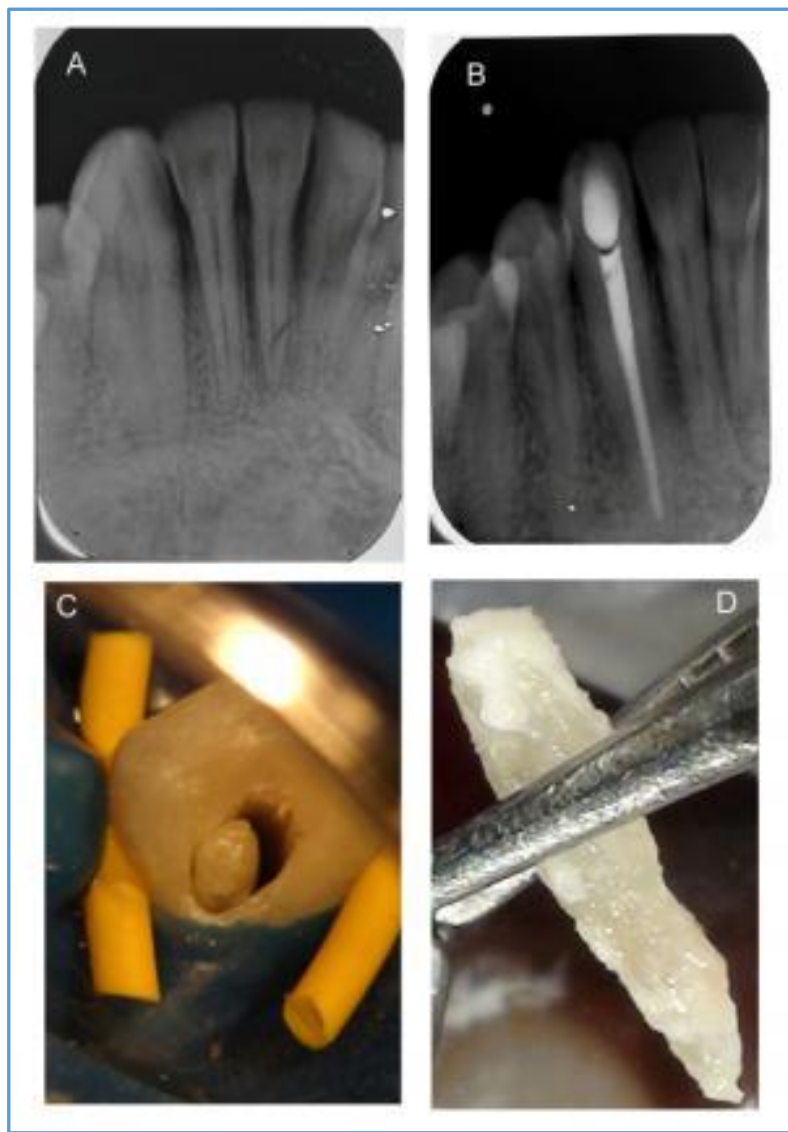

Figure 1. A. Pre-Operative Radiograph, B. Post-Operative Radiograph,

C. Pulp Stone Loosened from Canal Wall and Pulled Coronal Near Access with H-File. D. Removed Pulp Stone

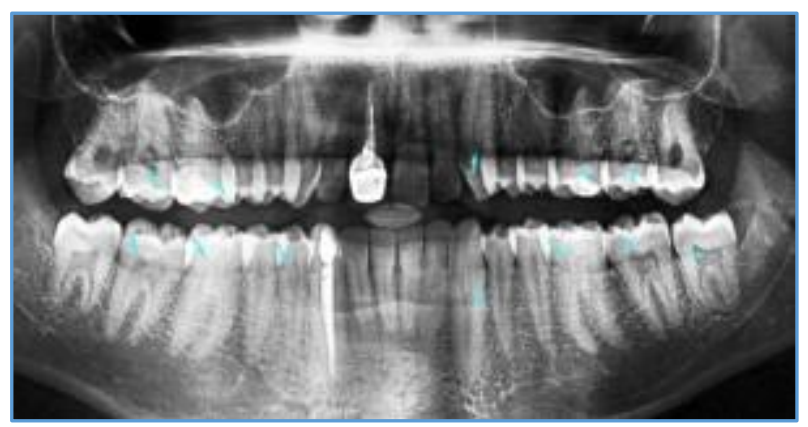

Figure 2. Orthopantomograph showing Pulpal Calcification in Multiple Teeth (Arrow)

\section{FINAL DIAGNOSIS}

This paper reports an uncommon case of occurrence of generalised pulp stones/ pulpal calcification. Such patients should be referred for genetic evaluation, because this condition is mostly associated with systemic or genetic disorders. Pulp stones rarely cause pain, but they may hinder canal instrumentation. Use of good illumination, magnification and instrumentation with ultrasonics may lead to success in such difficult and probably an overlooked clinical problem. 


\section{REFERENCES}

[1] Goga R, Chandler NP, Oginni AO. Pulp stones: a review. Int Endod J 2008;41(6):457-68.

[2] Ranjitkar S, Taylor JA, Townsend GC. A radiographic assessment of the prevalence of pulp stones in Australians. Aust Dent J 2002;47(1):36-40.

[3] Edds AC, Walden JE, Scheetz JP, et al. Pilot study of correlation of pulp stones with cardiovascular disease. J Endod 2005;31(7):504-6.

[4] Nayak M, Kumar J, Prasad LK. A radiographic correlation between systemic disorders and pulp stones. Indian J Dent Res 2010;21(3):369-73.

[5] Zeng J, Yang F, Zhang W, et al. Association between dental pulp stones and calcifying nanoparticles. Int J Nanomedicine 2011;6:109-18.
[6] Kajander E0, Çiftçioglu N. Nanobacteria: an alternative mechanism for pathogenic intra- and extracellular calcification and stone formation. Proc Natl Acad Sci U S A 1998;95(14):8274-9.

[7] Cook WA. Pulp stones and head pains. Dent Radiogr Photogr 1961;34:80-2.

[8] Jain P, Patni P, Hiremath $\mathrm{H}$, et al. Successful removal of a $16 \mathrm{~mm}$ long pulp stone using ultrasonic tips from maxillary left first molar and its endodontic management. J Conserv Dent 2014;17(1):92-5.

[9] Van Den Berghe JM, Panther B, Gound TG. Pulp stones throughout the dentition of monozygotic twins: a case report. Oral Surg Oral Med Oral Pathol Oral Radiol Endod 1999;87(6):749-51. 